\title{
Cytogenetic Effects of Low-Dose Tritiated Water in Human Peripheral Blood Lymphocytes-Experimental Studies on the Relative Biological Effectiveness and Chromosome Aberration Rate and CBMN in Human Blood Lymphocyte Irradiated by Tritium Low Dose Tritium $\beta$-Rays and ${ }^{60} \mathrm{Co} \gamma$-Rays
}

\author{
Bing Deng1,2, Jingwei Hou1*, Yi Quan',2, Lan Dong1, Zhaoyi Tan1 \\ ${ }^{1}$ Institute of Nuclear Physics and Chemistry, China Academy of Engineering Physics, Mianyang, China \\ ${ }^{2}$ Collaborative Innovation Center of Radiation Medicine of Jiangsu Higher Education Institutions, Suzhou, China \\ Email: "houzi4660@163.com
}

Received 17 September 2015; accepted 25 October 2015; published 28 October 2015

Copyright (C) 2015 by authors and Scientific Research Publishing Inc.

This work is licensed under the Creative Commons Attribution International License (CC BY).

http://creativecommons.org/licenses/by/4.0/

(c) †) Open Access

\section{Abstract}

In this study, the yields of unstable chromosome aberrations in human lymphocytes induced by $\beta$ particles from low-dose HTO have been measured. HTO was mixed with heparinized blood in varying amounts so that a dose of $6.24 \times 10^{-4} \mathrm{~Gy}$ to $1.23 \mathrm{~Gy}$ were delivered in 24 and $48 \mathrm{~h}$, respectively. After 72-h culture, the dicentric yield was measured as a function of dose to the blood and compared with data from ${ }^{60} \mathrm{Co} \gamma$-radiation. Using a linear-quadratic dose-effect relation to fit the experimental data, a significant linear contribution $\mathrm{Y}=0.062 \mathrm{D}+0.053 \mathrm{D}^{2}$ was found. The main difference between the coefficients for $\beta$ and $\gamma$-radiation was in the a values, indicating that HTO $\beta$-rays were more efficient, particularly at low doses. As per the theory of dual radiation, the relative biological effectiveness (RBE) of HTO $\beta$-particles relative to $\gamma$-rays is 2.21 at 0.06 Gy and decreases with increasing dose. Micronucleus yield at low doses was fitted to a linear equation $\mathrm{Y}=\mathrm{C}$ $+\alpha \mathrm{D}$, indicating that the RBE value of MN for HTO $\beta$-rays irradiation was between 1.46 and 2.17, which is similar in shape to the chromosome aberrations experiments. Thus, $\beta$-rays were found to

\footnotetext{
${ }^{*}$ Corresponding author.

How to cite this paper: Deng, B., et al. (2015) Cytogenetic Effects of Low-Dose Tritiated Water in Human Peripheral Blood Lymphocytes-Experimental Studies on the Relative Biological Effectiveness and Chromosome Aberration Rate and CBMN in Human Blood Lymphocyte Irradiated by Tritium Low Dose Tritium B-Rays and ${ }^{60}$ Co $\gamma$-Rays. Open Journal of Clinical Diagnostics, 5, 125-135. http://dx.doi.org/10.4236/ojcd.2015.54021
} 


\title{
be more efficient in producing two lesions with single ionizing tracks at low dose.
}

\section{Keywords}

\author{
Tritium, $\beta$-Radiation, Chromosome Aberrations, MN, RBE
}

\section{Introduction}

Tritium is a naturally occurring radionuclide widespread in nature as well as an important fission nuclide. Due to the rapid development of the nuclear industry, large amounts of tritium have been produced and released into the environment. Moreover, tritium has been widely used and is of great value to research in the fields of industry, biology, medicine, [1] and environmental science [2]. Tritium is present everywhere in the biosphere not only due to the similarity of its chemical properties with those of hydrogen, but also because under many circumstances, tritium can be incorporated into other molecules via an isotope exchange reaction with hydrogen. Even though the biological half-life of tritium is short (approximately 8 to 10 days), biologically occurring tritium is difficult to eliminate and its clearance half-time can reach up to 300 to 600 days [3]. The average kinetic energy of tritium $\beta$-rays is $5.72 \mathrm{KeV}$, with a maximum of $18.6 \mathrm{KeV}$. The average range of tritium $\beta$-rays is only 0.036 $\mathrm{cm}$ in air, thus it does not pose a radiation hazard outside the human body; however, tritium can cause internal radiation-mediated injury when ingested. According to the International Commission on Radiological Protection Publication 30 (ICRP30), at same concentrations in the air, the ratio of radiation hazard between tritium in the oxide (HTO) and elemental form (HT) is 25,000:1. Tritium can easily enter the human body via inhalation, ingestion, and penetration through skin, where it binds to DNA and RNA within cells causing direct radiation-mediated damage and chromosomal aberrations. As opposed to hydrogen, tritium is chemically toxic. Tritium poisoning can result in alterations in the central nervous system and hematopoietic system, and even induce carcinogenesis. Studies on the biological effect of tritium have shown that HTO can pose radiation hazards to the human body including acute radiation injury, somatic cell damage, reproductive cell damage, chromosomal aberrations, hazardous effects on growth and development of offspring, and other non-stochastic effects. In addition, the stochastic effects such as carcinogenic and genetic effects should not be ignored. Studies on the carcinogenic and genotoxic effects and the toxic effect on reproductive cells have revealed that the radiation weighting factor for tritium ranges between 1.7 and 2.4 [4]; hence, tritium is a radionuclide closely associated with public health.

DNA is very sensitive to ionizing radiation. Tritium from HTO can easily bind to DNA, thereby causing molecular and genetic toxicity. Chromosome aberration (CA) analysis of peripheral lymphocytes is widely used in the field of ionizing radiation, as a "biological dosimeter" to evaluate radiation dose received by an individual during a radiation-related accident. Meanwhile, it is also an important indicator for the evaluation of long-term effects of radiation, leading to great advances in studies on radiation-mediated carcinogenic effect and the relationship between genotoxic effect and chromosomal damage. Micronuclei (MN) are small nuclei outside the main nucleus, which consist of chromosomal fragments including one or more chromosomes lagging behind in anaphase and are indicative of partial chromosomal structure aberrations [5]. Similar to the CA method, peripheral lymphocytes are particularly sensitive to ionizing radiation, which can induce generation of $\mathrm{MN}$ in lymphocytes [6]. Significant increase in percentage of MN in peripheral lymphocytes is a sensitive indicator of radiation damage [7] [8]. In addition, there are no significant differences in the percentage of $\mathrm{MN}$ in peripheral lymphocytes exposed to radiation in vitro and in vivo, thus regression analysis of various radiation dosages can produce the same pattern of the fitted curve. In this study, chromosomal aberration at G0 phase in human lymphocytes caused by radiation from low-activity HTO $\beta$-rays and 60Co $\gamma$-rays was studied. The dose-response relationship was identified and compared with the results from cytokinesis-block micronucleus (CBMN) assay to determine the relative biological effects of HTO $\beta$-rays and ${ }^{60} \mathrm{Co} \gamma$-rays on the human body.

\section{Materials and Methods}

\subsection{Materials}

HTO with activity of $4.65 \times 10^{8} \mathrm{~Bq} / \mathrm{ml}$ was provided by the Research Institute of Nuclear Physics and Chemi- 
stry, China Academy of Engineering Physics, China. All other reagents were chemically pure and purchased from Sigma Co.

\subsection{Peripheral Lymphocyte Chromosomes Preparation}

Ten milliliters of venous blood were collected from 3 healthy subjects ( 2 male individuals and 1 female individual without smoking history, aged 25 to 28 years). Heparinized (500 kU/L) blood samples were cultured within $24 \mathrm{~h}$ after sample collection. Under strict sterile conditions, $0.4 \mathrm{ml}$ of whole blood sample was cultured in each flask. The culture medium was composed of $4 \mathrm{ml}$ RPMI 1640 solution, $1 \mathrm{~mL}$ calf serum, 25 mg phytohemagglutinin (PHA), and $0.1 \mathrm{~mL}(500 \mathrm{kU} / \mathrm{L})$ heparin, complemented with appropriate amounts of penicillin, streptomycin, and 5-bromo-deoxy uridine (BrdU). The final solution concentration $\mathrm{pH}$ was adjusted to 7.4 with $3.5 \% \mathrm{NaHCO}_{3}$. Blood culture was incubated in dark at $37.0^{\circ} \mathrm{C} \pm 0.5^{\circ} \mathrm{C}$ for $72 \mathrm{~h}$, after which, 0.1 to $100 \mu \mathrm{L} \mathrm{HTO}$ was added to blood culture at 24 and $48 \mathrm{~h}$, respectively. Equal volume of $0.9 \mathrm{~g} \% \mathrm{NaCl}$ solution was added in place of HTO to the control group. Colchicine at final concentration of $0.12 \mathrm{mg} / \mathrm{L}$ was added $3 \mathrm{~h}$ before culture termination. After the reaction was terminated, the supernatant was discarded using a pipette, followed by addition of $0.075 \mathrm{~mol} / \mathrm{L} \mathrm{KCl}$ for low-osmolality treatment. Subsequently, samples were fixed with freshly prepared fixative (methanol and acetic acid in 3:1 ratio). Slices of samples were air-dried and stained with 5\% Giemsa. For each sample, clear images of 100 to 500 well-dispersed, intact metaphase cells were counted and inspected under an oil immersion microscope.

\subsection{Preparation of Micronuclei of Peripheral Lymphocytes}

Similar to chromosomal culture, MN culture was carried out using micro-volume of whole blood culture with the modification of cytochalasin-B (Cyt-B) at a final concentration of $6 \mu \mathrm{g} / \mathrm{mL}$ added at the $44^{\text {th }}$ hour of cell culture. Samples were collected at $72 \mathrm{~h}$. During slide preparation, hypotonic solution was added to the samples, followed by immediate pre-fixation to preserve the intact cytoplasm during cell expansion. Cell suspension was mounted on clean slides soaked with room-temperature water or freezing cold solution for Giemsa staining. For each sample, 1000 transformed lymphocytes were inspected and the result was presented by proportion of MN cells (\%) and proportion of MN (\%).

\subsection{Irradiation Conditions}

Heparinized blood samples of the control group were treated with ${ }^{60} \mathrm{Co} \gamma$-rays at a source dose rate of $2.5 \times 10^{-4}$ Gy/sec for varying durations (same dose as that of the HTO-radiated samples). Samples that were irradiated with various doses were cultured and processed using the same method as the HTO group.

\subsection{Calculation of Average Absorbed Dose Generated by $\beta$-Radiation}

For lymphocytes that were exposed to radiation for t seconds in the suspension containing HTO, the average absorbed dose was calculated using the following the Formula (1):

$$
D \beta(t)=K E C_{0} \eta t(\mathrm{~Gy})
$$

where, $D \beta(t)$ represents the dose of $\beta$-radiation received at time $t, K$ is the conversion factor of $1.6 \times 10^{-13}$ $\mathrm{kg} \cdot \mathrm{Gy} \cdot \mathrm{MeV}^{-1}, E$ represents the average energy (5.7 keV) of $\beta$-radiation, $C_{0}$ is the activity in cell culture $\left(\mathrm{Bq} \cdot \mathrm{kg}^{-1}\right), \mathrm{t}$ is the radiation exposure time $(\mathrm{s}), \eta$ is the ratio of tritium concentration in lymphocyte and normal concentration, and $\eta$ value is 0.92 (a correction factor for tritium concentration in lymphocyte).

\section{Results}

\subsection{Dose-Response Relationship between the $\beta$-Ray Radiation Dose and the Radiation-Induced Chromosomal Aberrations in $\mathrm{G}_{0}$ Phase Lymphocytes}

First, for each radiation dose, a portion of sample slides was analyzed and the chromosomal aberrational frequency was obtained from a primary calculation. Then, the number of cells required for a permissible error of $20 \%$ was determined using the following Formula (2). 


$$
n=(1-p) \times 96.04 / p
$$

where, $p$ represents the percentage of mutated cells ((dic $+r) / c e l l)$ and $n$ represents the number of cells to be analyzed. Table 1 lists several types of unstable chromosomal aberrations, including acentric fragments, acentric rings, and dicentric chromosomes. Counts of dicentric chromosomes also included chromosomes with 2, 3, and 4 centromeres. However, acentric fragments were excluded from the analysis, because they are generally not considered as an indicator of radiation damage to chromosome due to instability.

As shown in Table 2, when the dosage rate is fixed, the value of dic/cell increased with the elevation of absorbed dose regardless the radiation dose. Through a distribution analysis of the number of centromeres, the issue of whether the radiation-induced damage of low-activity HTO complies with Poisson distribution can be determined through a Poisson distribution u-test. Previous studies have shown that, for uniform irradiation, when the conditions where $|\mathrm{u}|<1.96$ and the ratio of variance versus mean approaching 1.00 are satisfied, dicentric distribution among cells is in line with Poisson distribution. In this study, the u-test results of distribution analysis for each radiation dosage supported that the low-dose-HTO-radiation-induced distribution of dicentrics complied with Poisson distribution.

The data presented in Table 1 and Table 2 were then subject to a regression fitting. The degree of fitting $\left(\mathrm{r}^{2}\right)$ was calculated and the significance of the regression coefficient was determined. The fitting results regarding HTO $\beta$-ray-induced chromosomal aberration of peripheral lymphocytes are presented in Table 3, where Equation (3) was not applicable because of a negative spontaneous rate (c value) that did not agree with the actual situation. Equation (4) was also not applicable as its c value was higher than the spontaneous rate (spontaneous

Table 1. Unstable chromosome aberration yields and percentage of lymphocytes with chromosome damage induced by HTO $\beta$-particles.

\begin{tabular}{ccccccc}
\hline Average dose (Gy) & Total cells scored (n) & Total cells damaged & Centric rings & Dicentrics & Acentrics & Dic + r per cell \\
\hline 0 & 4380 & 0 & 0 & 2 & 0.0000 \\
0.006 & 4021 & 2 & & 2 & 0.0005 \\
0.01 & 3070 & 9 & 3 & 11 & 0.0010 \\
0.06 & 1476 & 23 & 2 & 10 & 68 & 0.0099 \\
0.12 & 1203 & 98 & 12 & 87 & 125 & 0.0696 \\
0.6 & 1423 & 257 & 19 & 175 & 116 & 0.1618 \\
1.3 & 1199 & 417 & 20 & 268 & 179 & 0.2942 \\
\hline
\end{tabular}

Table 2. Observed distribution and yields for dicentrics production when lymphocytes are irradiated with HTO $\beta$-particles.

\begin{tabular}{|c|c|c|c|c|c|c|c|c|c|}
\hline \multirow{2}{*}{$\begin{array}{c}\text { Average } \\
\text { dose(Gy) }\end{array}$} & \multirow{2}{*}{$\begin{array}{l}\text { Total cells } \\
\text { scored (n) }\end{array}$} & \multirow{2}{*}{$\begin{array}{c}\text { Total } \\
\text { dicentrics } \\
\text { observed }\end{array}$} & \multicolumn{4}{|c|}{ Distribution of dicentrics } & \multirow{2}{*}{$\begin{array}{c}\text { Mean } \\
\text { dicentrics } \\
\text { per cell (y) }\end{array}$} & \multirow{2}{*}{$\mathrm{u}$} & \multirow{2}{*}{$\delta^{2} / \mathrm{y} \pm \mathrm{SE}$} \\
\hline & & & 0 & 1 & 2 & 3 & & & \\
\hline 0 & 4380 & 0 & 4380 & & & & 0.00 & - & - \\
\hline 0.006 & 4421 & 2 & 4419 & 2 & & & 0.0005 & -0.346 & $0.995 \pm 0.025$ \\
\hline 0.01 & 3070 & 3 & 3067 & 3 & & & 0.001 & -1.120 & $0.977 \pm 0.041$ \\
\hline 0.06 & 1476 & 6 & 1470 & 6 & & & 0.004 & 0.386 & $1.013 \pm 0.042$ \\
\hline 0.12 & 1203 & 10 & 1193 & 10 & & & 0.008 & 0.827 & $1.032 \pm 0.063$ \\
\hline 0.6 & 1426 & 87 & 1339 & 84 & 3 & & 0.061 & 1.164 & $1.043 \pm 0.024$ \\
\hline 1.3 & 1199 & 175 & 1024 & 164 & 10 & 1 & 0.146 & 1.758 & $1.072 \pm 0.091$ \\
\hline 1.8 & 979 & 268 & 711 & 244 & 20 & 4 & 0.274 & 1.532 & $1.069 \pm 0.073$ \\
\hline
\end{tabular}


Table 3. Regression equations test of dic $+\mathrm{r}$ induced by irradiation of HTO $\beta$-rays.

\begin{tabular}{cccc}
\hline No. & Equation & $\mathrm{r}^{2}$ & $p$ \\
\hline 1. & $\mathrm{Y}=(0.001 \pm 0.004)+(0.062 \pm 0.018) \mathrm{D}+(0.053 \pm 0.010) \mathrm{D}^{2}$ & 0.995 & $p<0.01$ \\
2 & $\mathrm{Y}=(0.120 \pm 0.008) \mathrm{D}^{(1.481 \pm 0.131)}$ & 0.992 & $p<0.01$ \\
3 & $\mathrm{Y}=(-0.006 \pm 0.008)+(0.152 \pm 0.010) \mathrm{D}$ & 0.972 & $p<0.01$ \\
4 & $\mathrm{Y}=(0.004 \pm 0.005)+(0.115 \pm 0.011) \mathrm{D}^{(1.542 \pm 0.166)}$ & 0.991 & $p<0.01$ \\
\hline
\end{tabular}

rate of dic $+r$ in each cell was $0.05 \%$ ). Results of regression analyses regarding the dose-response relationship of HTO-radiated peripheral lymphocytes vary among different research groups, mainly due to the differences in experimental operation, cell reaction time, cytotoxicity analysis, and data processing. Bocian et al. [9] showed that treating peripheral lymphocytes with 2-h HTO $\beta$-ray radiation at a dose rate of 2.4 to $21.3 \mathrm{mGy} \cdot \mathrm{min}^{-1}$ could produce a linear-quadratic dose-response equation; however, the reaction induced by $\mathrm{HTO}$ at a higher dose rate was more fitted to the equation $\mathrm{Y}=\mathrm{aD}^{\mathrm{n}}(\mathrm{n}=1.45)$. In case of long-duration and low-dose-rate radiation (a radiation duration of $53 \mathrm{~h}$ and a dose rate of 0.09 to $0.80 \mathrm{mGy} \cdot \mathrm{min}^{-1}$ ), the induced chromosomal aberration was more in line with a linear equation. Pross et al. [10] found that the chromosomal aberrational frequency fitted the linear-quadratic equation when cells were irradiated with $\mathrm{HTO} \beta$-rays within a dose range of 0.1 to $4.1 \mathrm{~Gy}$ at a dose rate of 0.07 to $1.0 \mathrm{mGy} \cdot \mathrm{min}^{-1}$ for $24 \mathrm{~h}$. Taken together, despite the difference in dose-response equations of chromosomal aberration obtained from different studies, it is generally believed that the chromosomal aberrational frequency is associated with both HTO dose and dose rate. In this study, where a low-dose and long-duration radiation conditions were employed and considering that both, the goodness of fit and the simplicity of calculation, Equation (1), $\mathrm{Y}=0.001+0.062 \mathrm{D}+0.053 \mathrm{D}^{2}$, was adopted to determine the effect of HTO $\beta$-ray radiation $\left(\mathrm{r}^{2}=0.995, p<0.01\right)$.

\subsection{Relative Biological Effectiveness (RBE) of HTO $\beta$-Radiation in Inducing Human Chromosomal Aberrations}

RBE values of different types of radiations rely on multiple factors including major physical factors such as dosage of radiation, dose rate, and linear energy loss, while sensitivity to radiation and capability of regeneration and compensation are biological factors. Generally, RBE of different types of radiations can be approximately expressed by the ratio of linear energy transfer (LET), as a higher LET value indicates more concentrated energy in radiated tissue, thereby inducing more significant biological effects. However, considering the complexity of the interaction between radiation and the target substance as well as the intertwined relationship between this interaction and the extreme complexity of biological processes, RBE is also dependent on the biological species exposed to radiation, endpoints of observed biological effect, and the shape of the dose-response curve in addition to the physical conditions of exposure. Therefore, studies on RBE are more beneficial in elucidating the relationship between energy deposition and biological effect.

In this study, RBE of low-dose HTO $\beta$-radiation was determined using ${ }^{60} \mathrm{Co} \gamma$-radiation as control, which induced similar chromosomal dic $+\mathrm{r}$ aberration frequency. The experiment was performed with HTO $\beta$-radiation at a dose rate of 0.024 - 1 to $230 \mathrm{mGy} \cdot \mathrm{min}^{-1}$ within a dose range of 0 to $1.8 \mathrm{~Gy}$. The control group received ${ }^{60} \mathrm{Co}$ $\gamma$-radiation at a dose rate of $14.4 \mathrm{mGy} \cdot \mathrm{min}^{-1}$ within a dose range of 0 to $2.2 \mathrm{~Gy}$. Table 4 demonstrates the yields of chromosomal aberrations including acentrics, dicentrics, and ring aberrations (dic $+\mathrm{r}$ ) that were induced by $\gamma$ -radiation in vitro.

Based on the results shown in Table 4, an optimal regression equation, $\mathrm{Y}=0.001+0.013 \mathrm{D}+0.045 \mathrm{D}^{2}\left(\mathrm{r}^{2}=\right.$ 0.996, $p<0.01$ ), for $\gamma$-radiation was obtained. The effect of HTO $\beta$-radiation for the induction of dicentrics plus ring aberrations was similar to other low-dose LET radiation, fitting the pattern of $\mathrm{Y}=\mathrm{aD}+\mathrm{bD}^{2}$. Comparison of the coefficients in the equations for $\beta$ - and $\gamma$-radiation revealed that the major difference resided in the $a$-value, which was not associated with the dose rate but with the LET value of different types of radiations. The results of coefficient ratio $\lambda(a / b)$ of $\beta$ - and $\gamma$-radiations showed that, for low-dose HTO $\beta$-radiation, the effect of $a \mathrm{D}$ value on the increase in the chromosomal aberration yield was more significant than that of ${ }^{60} \mathrm{Co} \gamma$-radiation, with a higher RBE value. As the radiation dose increased, the effect of the $b \mathrm{D}^{2}$ value on the increase in the chromosomal aberration yield gradually increased while the effect of the $a \mathrm{D}$ value gradually decreased. How- 
Table 4. Unstable chromosome aberration yields and percentage of lymphocytes with chromosome damage induced by ${ }^{60} \mathrm{Co}$ $\gamma$ rays.

\begin{tabular}{ccccccc}
\hline Average dose (Gy) & Total cells scored (n) & Total cells damaged & Centric rings & Dicentrics & Acentrics & Dic $+\mathrm{r}$ per cell \\
\hline 0.05 & 3892 & 7 & 2 & 5 & 0.0005 \\
0.1 & 2098 & 43 & 2 & 41 & 0.0010 \\
0.13 & 1246 & 59 & & 5 & 54 & 0.0040 \\
0.25 & 1346 & 104 & 1 & 10 & 93 & 0.0082 \\
1.0 & 1133 & 177 & 15 & 59 & 103 & 0.0653 \\
1.7 & 1008 & 242 & 13 & 131 & 98 & 0.1429 \\
2.2 & 855 & 234 & 21 & 193 & 200 & 0.2503 \\
\hline
\end{tabular}

ever, when the radiation dose increased to a certain level, the effect of $a \mathrm{D}$ value was negligible. Therefore, RBE of low-activity HTO could be calculated by using Formula (3). The relationship between HTO dose and RBE is presented in Figure 1.

$$
R B E=D_{\gamma} / D_{\beta}
$$

Figure 2 indicates that low-dose HTO $\beta$-radiation had a more significant effect on the subjects than that of $\gamma$ radiation at the same dose. As displayed in Figure 1, within the low dose range observed in this study, the maximum value of RBE of HTO radiation was 2.17 when the HTO radiation dose was only $0.06 \mathrm{~Gy}$. As the HTO dose increased, the RBE value gradually decreased and finally stabilized at a value of 1.29 while the HTO dose was within a range of 1 to $2 \mathrm{~Gy}$.

\subsection{Analysis of in Vitro Radiation-Induced MNs in Human Peripheral Blood Lymphocytes Exposed to HTO $\beta$ - and ${ }^{60} \mathrm{Co} \gamma$-Rays}

Figure 3 shows MN in non-irradiated dual-nucleus cytokinesis-blocked (CB) cells and radiated dual-nucleus CB cells detected by the CBMN assay. Round and oval shaped MNs with smooth boundaries were located within intact cytoplasm with a diameter $1 / 16$ to $1 / 3$ of the main nucleus. The MNs were stained with same color as the main nucleus and were not interconnected with the main nucleus. Table 5 presents the MN rates and proportion of cells with MN induced by HTO $\beta$ - and ${ }^{60} \mathrm{Co} \gamma$-radiation in human peripheral blood lymphocytes.

A curve fitting for the dose-response relationship was performed for MN induction by HTO and ${ }^{60} \mathrm{Co}$ radiations based on results in Table 5. The fitting result is displayed in Figure 4, which indicates that the dose-response relationship within a dose range of 0 to $1.8 \mathrm{~Gy}$ fits the linear regression equation,

$$
Y=C+\alpha D
$$

where $Y$ is the dose (D)-dependent $\mathrm{MN}$ incidence and $\alpha$ is the regression coefficient. The optimal regression equation was $Y=(3.44 \pm 3.36)+(31.78 \pm 3.95) \mathrm{D}\left(\mathrm{r}^{2}=0.941, p<0.01\right)$ for $\mathrm{HTO}$ and $\mathrm{Y}=(5.50 \pm 0.91)+(12.72 \pm$ 1.06) $\mathrm{D}\left(\mathrm{r}^{2}=0.973, p<0.01\right)$ for ${ }^{60} \mathrm{Co}$. According to the above equations, the ratio of RBE between ${ }^{60} \mathrm{Co} \gamma$-rays and HTO $\beta$-rays for MN generation was 1.46 to 2.17 when using the MN rate as the biological endpoint (Table 6). As shown in Table 6, RBE varied significantly for low-dose radiation.

\section{Discussion}

\subsection{Dose-Response Relationship for HTO $\beta$-Radiation-Induced Chromosomal Damage}

Ionizing radiation can induce various types of chromosomal aberrations, among which, dic $+r$ is the most common indicator for biological dose evaluation. The benefit of using dic $+r$ for aberration evaluation is that the incidence of spontaneous dic $+r$ is relatively low in non-irradiated controls $(0.5 \%$ to $5 \%$ o per cell) while high incidence of this event can be induced by radiation. Moreover, the morphology and structure of dic $+r$ is easily identified. Types of chromosomal aberrations of lymphocytes induced by ionizing radiation vary with the stage of cell cycle when cells are irradiated. Cells exposed to ionizing radiation during $G_{0}$ phase of the cell cycle often 


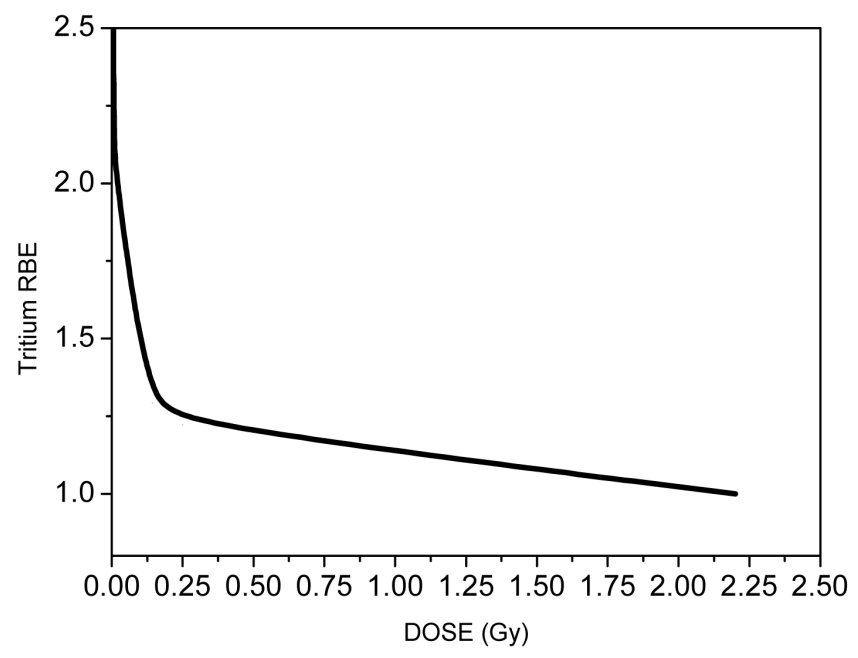

Figure 1. Dose dependence of RBE for HTO $\beta$-radiation.

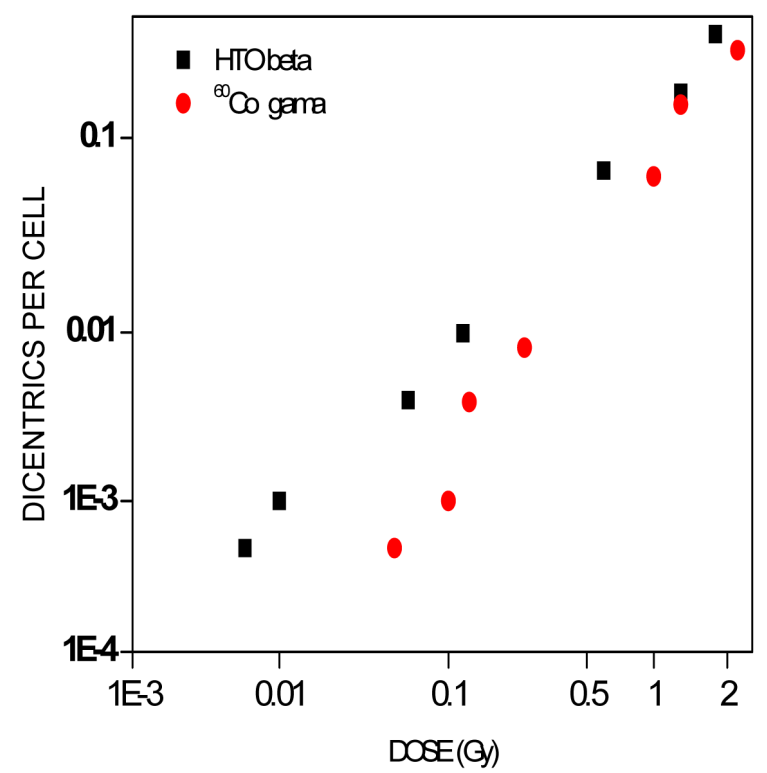

Figure 2. The yield of dicentrics per cell plotted against dose for lymphocytes irradiated with HTO and $\gamma$ rays.
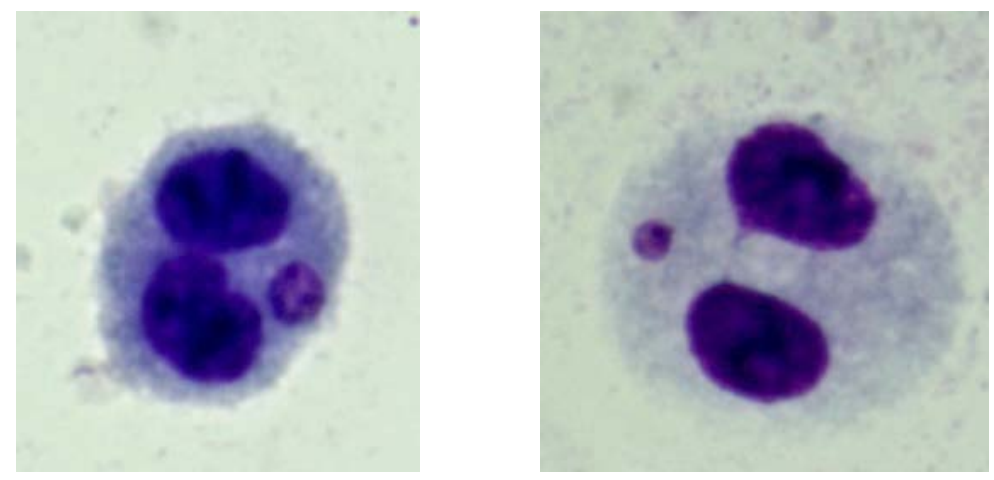

Figure 3. CBMN induced by HTO $\beta$ rays in human peripheral blood lymphocytes. 


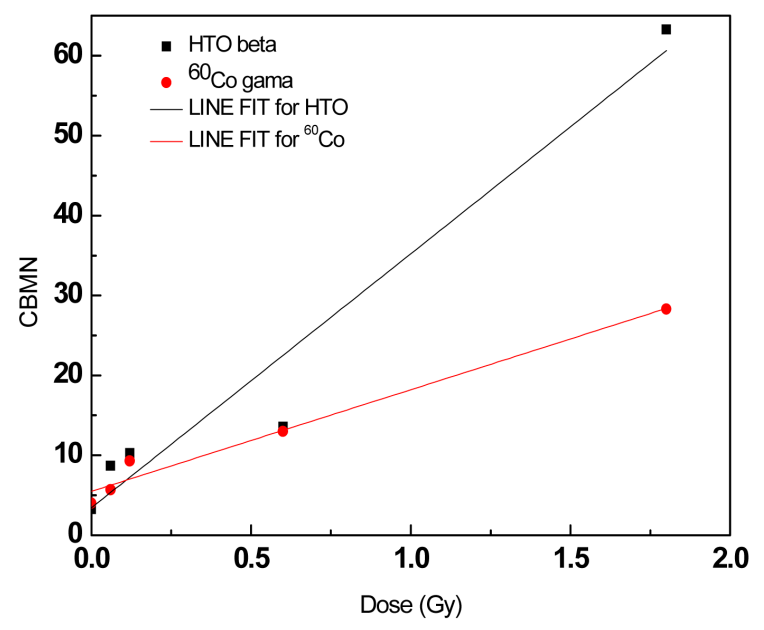

Figure 4. Dose response curve for the induction of CBMN by HTO $\beta$-Particles and ${ }^{60} \mathrm{Co} \gamma$-rays.

Table 5. Micronuclear rates induced by HTO $\beta$-particles and ${ }^{60} \mathrm{Co} \gamma$-rays.

\begin{tabular}{cccccc}
\hline \multirow{2}{*}{$\begin{array}{c}\text { Average } \\
\text { dose (Gy) }\end{array}$} & $\begin{array}{c}\text { Total cells scored } \\
\text { HTO/ }{ }^{60} \text { Co }\end{array}$ & \multicolumn{2}{c}{ MN } & \multicolumn{2}{c}{ The cells with MN } \\
\cline { 3 - 6 } & Total MN observed & MN/cell (\%) & Total cells with MN & cells with MN/cell (\%) \\
\hline 0 & $3000 / 3000$ & $10 / 12$ & $3.3 / 4.0$ & $10 / 12$ & $3.3 / 4.0$ \\
0.006 & $2250 / 3000$ & $18 / 12$ & $8.0 / 4.0$ & $16 / 11$ & $7.1 / 3.7$ \\
0.01 & $3000 / 3000$ & $21 / 15$ & $7.0 / 5.0$ & $21 / 7$ & $7.0 / 2.3$ \\
0.06 & $3000 / 3000$ & $26 / 17$ & $8.7 / 5.7$ & $24 / 16$ & $8.0 / 5.3$ \\
0.12 & $3000 / 3000$ & $31 / 28$ & $10.3 / 9.3$ & $27 / 23$ & $9.0 / 7.7$ \\
0.6 & $1838 / 3000$ & $25 / 39$ & $13.6 / 13.0$ & $20 / 36$ & $10.9 / 12.0$ \\
1.3 & $3000 / 3000$ & $99 / 42$ & $33.0 / 14.0$ & $91 / 32$ & $30.3 / 10.7$ \\
1.8 & $3000 / 3000$ & $190 / 85$ & $63.3 / 28.3$ & $175 / 75$ & $58.3 / 25.0$ \\
\hline
\end{tabular}

Table 6. Relative biological effectiveness values of micronucleus induced by ${ }^{60} \mathrm{Co} \gamma$-rays and HTO $\beta$-rays in human peripheral blood lymphocytes.

\begin{tabular}{cccc}
\hline & Dose $(\mathrm{Gy})$ & \multicolumn{2}{c}{ RBE } \\
\cline { 2 - 4 } CBMN(\%) & ${ }^{60} \mathrm{Co} \gamma$ & HTO $\beta$ & $\mathrm{D}_{\gamma} \mathrm{D}_{\beta}$ \\
\hline 8.7 & 0.11 & 0.06 & 1.83 \\
10.3 & 0.26 & 0.12 & 2.17 \\
13.6 & 1.20 & 0.60 & 2.00 \\
33.0 & 1.90 & 1.30 & 1.46 \\
\hline
\end{tabular}

have chromosome-type aberrations whereas irradiation during $S$ and $G_{2}$ phase induces chromatid-type aberrations. In this study, the exposure of cells at the metaphase of first mitosis to $\beta$-radiation mostly resulted in DNA double-strand breaks, which increased with an increase in radiation dose. In this study, we used HTO $\beta$-radiation within a dose range of 0 to $1.8 \mathrm{~Gy}$ and a dose rate range of 0.024 to $1.230 \mathrm{mGy} \cdot \mathrm{min}^{-1}$. Using 4 different regression equations to fit the measured data, we found that the results satisfied a linear-quadratic mode, $\mathrm{Y}=\mathrm{aD}+\mathrm{bD} \mathrm{D}^{2}$, and obtained the optimal regression equation, $\mathrm{Y}=0.047 \mathrm{D}+0.056 \mathrm{D}^{2}\left(\mathrm{r}^{2}=0.994, p<0.01\right)$. This model indicates that dicentrics aberration requires 2 breaks on 2 separate chromatids. The aD value reflected that radiation hit 
through a single ionized track and caused breaks on 2 chromatids, which were then rearranged to form 1 dicentric; this value is linearly related to radiation dose but not related to dose rate. The $\mathrm{bD}^{2}$ value indicated that radiation through 2 ionized tracks produced a break on each of chromatids, followed by dicentrics formation via rearrangement; this value was dependent on dose rate. Therefore, based on the obtained fitting equation, combined with the Bender's hypothesis on the mechanism of chromosomal aberration, [11] and the theory of two-level radiations [12], we proposed that when the dose of HTO $\beta$-rays equals to the ratio of coefficient $\lambda(\mathrm{a} / \mathrm{b})$, the above two causes equally contribute to the incidence of radiation-induced chromosomal aberrations. However, when the dose is lower than the $\lambda$ value, chromosomal aberrations are mainly caused by single-track radiation [13]. The $\lambda$ value is 0.29 Gy for -rays, 0.42 Gy for X-rays, [14] and $1.17 \mathrm{~Gy}$ for HTO $\beta$-rays, which mainly results from different LET values. The relatively high value of $\gamma$ of $\beta$-rays indicates that the single-track $\beta$-particle radiation is more efficient than $\gamma$ and $\mathrm{X}$ radiation in inducing breaks on 2 chromatids.

\subsection{Comparison of HTO $\beta$ and $\gamma$-Radiation-Induced Chromosomal Aberrations and RBE}

Because of the differences in biological species, biological endpoints, and radiation properties, it is difficult to unify various results as the biological effect of HTO. Based on the difference in LET value between $\beta$-rays and $\gamma$-rays $\left(0.752 \times 10^{-9} \mathrm{~J} \cdot \mathrm{m}^{-1}\right.$ for $\beta$-rays and $0.0382 \times 10^{-9} \mathrm{~J} \cdot \mathrm{m}^{-1}$ for $\gamma$-rays), the difference in chromosomal aberrational incidences induced by $\beta$ - and $\gamma$-radiations can be obtained. Hence, the biological effect of HTO $\beta$-radiation can be determined using $\gamma$-radiation as reference. When irradiating lymphocytes with the same dose of $\gamma$ radiation, the dose-response relationship for high-LET radiation is in linear relationship whereas low-LET radiation results in curve relationship. Thus, the relative effect of high-LET radiation decreases with the dose elevation. In this study, we observed a curve-shaped dose-response relationship induced by HTO $\beta$-radiation and RBE decreased as the radiation dose increased. The possible mechanisms behind this phenomenon might be as follows. First, as opposed to $\gamma$-radiation, HTO $\beta$-rays can enter cells and participate in the construction of DNA molecules. In addition to the effect of $\beta$-radiation, decay of ${ }^{3} \mathrm{H}$ can induce nuclear transformation and leave a ${ }^{3} \mathrm{He}$-containing molecule at the site of decay. Depending on the presence of ${ }^{3} \mathrm{He}$-containing molecule and the specific location of ${ }^{3} \mathrm{He}$ in this molecule, the ${ }^{3} \mathrm{He}$-induced aberrations might be more dangerous compared with those caused by $\beta$-particle ionizing radiation [15]. This is due to the fact that aberrational endpoints induced by ${ }^{3} \mathrm{He}$ as opposed to ${ }^{3} \mathrm{H}$ are not easily recognized by the DNA damage-repair system, resulting in the accumulation of the damage in DNA molecules and finally loss of gene fragments. This type of post-transformation DNA double-strand breaks accounts for $1 / 8$ of total events [16]. Second, when high-dose radiation is applied, there are no significant differences in intracellular energy deposition of ionized tracks between different types of radiations, whereas energy deposition is significantly different with low-dose radiation. Finally, a higher aberrational efficiency of a low-dose and long-duration HTO radiation is mostly due to the specific biological mechanism of tritium. The $\beta$-particle is known to produce short-range radiation. Within their radiation range, tritium $\beta$-particles have an average density ionization of $4.7 \mathrm{keV} / \mu \mathrm{m}$, significantly higher than that of $200 \mathrm{KeV} \mathrm{X}$-radiation (1.7 $\mathrm{keV} / \mu \mathrm{m})$ and ${ }^{60} \mathrm{Co} \gamma$-radiation $(0.22 \mathrm{keV} / \mu \mathrm{m})$. Therefore, as tritium accumulates in the nucleus, the radiation dose that can generate biological effect increases and its effect is amplified.

In addition, previous studies on the biological effect of tritium have revealed that the dose-response curve varies due to differences in selection of the biological endpoint and dose rate. When using survival rate of primary oocyte as the biological endpoint, the dose-response curve fits the least-square regression curve and RBE reaches approximately 3 under low-dose radiation, whereas with dominant lethal mutation of oocytes as the endpoint for dose-response curve fitting, RBE reaches 2.8. It has been previously reported that RBE for low dose HTO $\beta$-radiation reached 2.3 to 2.7 when chromosomal aberration of peripheral lymphocytes was selected as the endpoint and ${ }^{60} \mathrm{Co} \gamma$-radiation was used as reference [17] [18], consistent with findings from this study.

Our results indicate that low-dose $\beta$-radiation is more powerful than $\gamma$-radiation at the same dose, in terms of the ability to induce chromosomal aberration, making HTO a potential genetic hazard. Hence, protection from HTO should be emphasized. Moreover, according to Bender's hypothesis on chromosomal aberration mechanism, chromosomal aberration results from DNA double-strand breaks and the subsequent incorrect rearrangement of these broken ends. Unrepaired, single-strand, DNA breaks appear as chromatid fissures in the following metaphase, which are not genuine chromosomal breaks. Although HBO $\beta$-radiation-induced damage comprises of mainly DNA single-strand breaks, this type of break can be repaired, whereas DNA double-strand breaks are difficult or impossible to repair despite their lower incidence [18]. Therefore, in this study, only the DNA 
double-strand breaks in metaphase were analyzed with the exclusion of chromatid fissures resulting from DNA single-strand breaks. Even though DNA molecular break is not considered as a genotoxic effect, aberrant DNA repair can lead to various levels of mutations in human body, including gene mutation, chromosomal aberration, and metabolic disorders. Taken together, it is insufficient to evaluate HTO-induced genetic effect in humans based on the study of chromosomal aberration of lymphocytes. Thus, in-depth and comprehensive studies are required to further explore the mechanisms underlying HTO-induced genetic effects.

\subsection{Comparison of CB MNs Induced by HTO $\beta$-Rays and $\gamma$-Ray and Their RBE}

Studies on mice and healthy human blood samples exposed to X-radiation and ${ }^{60}$ Co $\gamma$-radiation [19]-[23] have confirmed a good linear relationship between the MN rate and radiation dosage within a certain dose range. Some studies used the fitted linear regression equation to evaluate the biological dose that the subjects were exposed to during accidents [24]. However, most studies were focused on the events occurring under high-dose radiations or accidental conditions, therefore the question whether low-dose-radiation-induced $\mathrm{MN}$ rate in human peripheral lymphocytes can be employed in the evaluation of radiation damage remains unanswered. Thus, the dose-response relationship for low-dose radiation needs to be identified and the measurement method of CB MN rate needs to be standardized. In the present study, human peripheral blood lymphocytes were irradiated with HTO and ${ }^{60} \mathrm{Co} \gamma$-rays at a dose range of 0 to $1.8 \mathrm{~Gy}$. MN formation in peripheral lymphocytes was investigated and the dose-response relationship was identified for different types of radiations at different radiation doses. The results demonstrated that the MN rate in lymphocytes positively correlated with the radiation dose when the dose was within a range of 0 to $1.8 \mathrm{~Gy}(p<0.01)$, consistent with the results of high-dose radiation in previous studies [25]-[28]. The RBE value obtained using CB MN rate as an endpoint was consistent with that obtained using chromosomal aberration as an endpoint, which was in line with conclusion [29] a previous report by International Atomic Energy Agency (IAEA). Assessment of MN as a tool to evaluate the biological dose of radiation is quicker, simpler, and cost-effective compared with chromosome aberration evaluations. Therefore, MN assay can serve as a rapid screening test to evaluate chromosomal damage, suitable for rapid dose estimation for a large number of subjects involved in accidents or emergencies [30] [31].

\section{Fund}

This work was supported by a grant from Innovation Fund of Institute of Nuclear Physics and Chemistry (2013CX02); Science and Technology Development Fund of China Academy of Engineering Physics (2013B0301036); Science and Technology Development Fund of China Academy of Engineering Physics (2014B0301035).

\section{References}

[1] Filer, C.N. (2009) Tritium Labelled Photoaffinity Agents. Radioanalytical and Nuclear Chemistry, 281, 521-530.

[2] Dassi, L. (2010) Use of Chloride Mass Balance and Tritium Data for Estimation of Groundwater Recharge and Renewal Rata in an Unconfined Aquifer from North Africa: Case Study from Tunisia. Environ Earth, 60, 861-871.

[3] IAEA (1996) International Basic Safety Standards for Protection against Ionizing Radiation and for the Safety of Radiation Sources IAEA Safety. Series No. 115, Vienna.

[4] Galeriu, D., Melintescu, A. and Takeda, H. (2007) Risk from Tritium Exposure, IRPA. Regional Congress for Central and Eastern Europe, 9, 24-28.

[5] Fenech, M. (2010) The Lymphocyte Cytokinesis-Block Micronucleus Cytomeassay and Its Application in Radiation Biodosimetry. Health Physics, 26, 11-17.

[6] Samavat, H. and Mozdarani, H. (2004) Chromosomal Abrrations in Iranian Radiation Workers Due to Chronic Exposure of X-Irradiation. International Journal of Low Radiation, 1, 216-222. http://dx.doi.org/10.1504/IJLR.2004.003873

[7] Fenech, M. (2007) Cytokinesis-Block Micronucleus Cytome Assay. Nature Protocols, 2, 1084-1104. http://dx.doi.org/10.1038/nprot.2007.77

[8] Thomas, P. and Fenech, M. (2011) Cytokinesis-Block Micronucleus Cytome Assay in Lymphocytes. Methods in Molecular Biology, 682, 217-234. http://dx.doi.org/10.1007/978-1-60327-409-8_16

[9] Bocian, E., Ziemb_Zak, B., Rosiek, O., et al. (1977) The Use of Nitroaromatic Compounds as Hypoxic Cell Radiosensitizers. Current Topics in Radiation Research Quarterly, 8, 347-398. 
[10] Prosser, J.S., Lloyd, D.C., Edwards, A.A., et al. (1984) Biological Dosimetry in Radiological Protection: Recent Developments. Journal of the Society for Radiological Protection, 4, 21.

[11] Bender, M.L. (1962) Molecular Biochemistry. Science, 138, 672-673. http://dx.doi.org/10.1126/science.138.3541.672

[12] Dobson, R.L. (1986) Health Effects of Low Level Radiation: Carcinogenesis, Teratogenesis, and Mutagenesis Effects of Low Level Radiation. Seminars in Nuclear Medicine, 16, 106-117. http://dx.doi.org/10.1016/S0001-2998(86)80024-1

[13] IAEA (1986) Biological Dosimetry: Chromosomal Aberration Analysis for Dose Assessment. Technical Report Series No. 26. IAEA, Vienna.

[14] Sreedevi, B., Shankaanaayanan, N. and Rao, B.S. (1997) The Induction of Micronuclei and Chromosomal Aberrations in Human Lymphocytes Irradiated in Vitro with Fission Neutrons. Radiation Protection and Environment, 20, 21-25.

[15] Balonov, M.I., Likhtarev, I.A. and Moskalev, I.Y. (1984) The Metabolism of 3H Compounds and Limits for Intakes by Workers. Health Physics, 47, 761-773. http://dx.doi.org/10.1097/00004032-198411000-00008

[16] Svensson, H., Hanson, G.P. and Zsdanzky, K. (1990) The IAEA/WHO TL Dosimetry Service for Radiotherapy Centres 1969-1987. Acta Oncologica, 29, 461-467. http://dx.doi.org/10.3109/02841869009090030

[17] Tawn, E.J. and Thuerens, H. (2009) Dose Response Relationships for Chromosome Aberrations Induced by Low Doses of Alpha-Particle Radiation. Radiation Protection Dosimetry, 135, 268-271. http://dx.doi.org/10.1093/rpd/ncp116

[18] Fedorenko, B.S. (2006) Radiobiological Effects of Corpuscular Radiations: Radiation Safety of Space Flights. Nauka, Moscow. (In Russian)

[19] Tanaka, K., Sawada, S. and Kamada, N. (1994) Relative Biological Effectiveness and Dose Rate Effect of Tritiated Water on Chromosomes in Human Lymphocytes and Bone Marrow Cells. Mutation Research Letters, 323, 53-61. http://dx.doi.org/10.1016/0165-7992(94)90045-0

[20] Johnson, J.R., Myers, D.K., Jackson, J.S., Dunford, D.W., Gragtmans, N.J., Wyatt, H.M., et al. (1995) Relative Biological Effectiveness of Tritium for Induction of Myeloid Leukemia in CBA/H Mice. Radiation Research, 144, 82-89. http://dx.doi.org/10.2307/3579239

[21] Kozlowski, R., Bouffler, S.D., Haines, J.W., Harrison, J.D. and Cox, R. (2001) In Utero Haemopoietic Sensitivity to Alpha, Beta or X-Irradiation in CBA/H Mice. International Journal of Radiation Biology, 77, 805-815. http://dx.doi.org/10.1080/09553000110053161

[22] Ueno, A.M., Furuno-Fukushi, I. and Matsudaira, H. (1982) Induction of Cell Killing, Micronuclei, and Mutation to 6-Thioguanine Resistance after Exposure to Low-Dose-Rate $\gamma$ Rays and Tritiated Water in Cultured Mammalian Cells (L5178Y). Radiation Research, 91, 447-456. http://dx.doi.org/10.2307/3575884

[23] Yamada, T., Yukawa, O., Asami, K. and Nakazawa, T. (1982) Effect of Chronic HTO $\beta$ or ${ }^{60}$ Co $\gamma$ Radiation on Preimplantation Mouse Development in Vitro. Radiation Research, 92, 359-369. http://dx.doi.org/10.2307/3576012

[24] IAEA (2001) Cytogenetic Analysis for Radiation Dose Assessment. Technical Report Series No. 405. IAEA, Vienna.

[25] Satow, Y., Hori, H. and Lee, J.-Y. (1989) Teratogenic Effect of Fission Neutron and Tritium Water on Rat Embryo. Journal of UOEH, 11, 416-431.

[26] Revina, V.S., Voronin, V.S., Lemberg, V.K. and Sukhodoev, V.V. (1984) Comparative Evaluation of the Tumorigenic Effect of Chronic Exposure to Tritium Oxide and External $\gamma$ Radiation. Radiobiologiia, 24, 697-700.

[27] Chopra, C. and Heddle, J.A. (1988) Cytogenetic Measurements of the Relative Biological Effectiveness of Tritium. Report INFO-0287. Atomic Energy Control Board, Ottowa.

[28] Vulpis, N. (1984) The Induction of Chromosome Aberrations in Human Lymphocytes by in Vitro Irradiation with $\beta$ Particles from Tritiated Water. Radiation Research, 97, 511-518. http://dx.doi.org/10.2307/3576141

[29] IAEA (2000) The Radiological Accident in Istanbul. IAEA, Vienna.

[30] Schreiber, G.A. (1992) An Automated Flow Cytometric Micronucleus Assay for Human Lymphocytes. International Journal of Radiation Biology, 62, 695-709. http://dx.doi.org/10.1080/09553009214552651

[31] Tates, A.D., Van Welie, M.J. and Ploen, J.S. (1990) The Present Status of Automated Micronucleus Test for Lymphocytes. International Journal of Radiation Biology, 58, 813-825. http://dx.doi.org/10.1080/09553009014552191 